Annals of Glaciology $5 \quad 1984$

(c) International Glaciological Society

\title{
ICE FLOW LEADING TO THE DEEP CORE HOLE AT DYE 3,
}

\section{GREENLAND*}

\author{
by
}

I. M. Whillans,

(Department of Geology and Mineralogy and Institute of Polar Studies, Columbus, Ohio 43210, U.S.A.)

K. C. Jezek,

(Geophysical and Polar Research Center, University of Wisconsin-Madison, 1215 W. Dayton Street, Madison, Wisconsin 53706, U.S.A.)

A. R. Drew

(Department of Geodetic Science and Surveying, and Institute of Polar Studies, Ohio State University, Columbus, Ohio 43210, U.S.A.)

\section{and N. Gundestrup}

(Geophysical Isotope Laboratory, University of Copenhagen, Haraldsgade 6, DK-2200 Copenhagen N, Denmark)

\begin{abstract}
ABST RACT
Detailed studies of the last $20 \mathrm{~km}$ of the flow1 ine leading to the core hole at Dye 3 Greenland, provide a description of ice flow over and around basal hills. The surface pattern is very simple. Velocity vectors are nearly parallel to one another and the largest variations in velocity are speed changes along the direction of flow. The surface elevation is stepped and the speed is faster than average where the surface slope is steepest. These positions correspond to basal highs, and the surface velocity increases as expected, based on the decrease in ice thickness, which indicates that most of the ice thickness must vary in velocity as does surface ice. Further support for this comes from the form of an internal radio-reflecting layer, which, in general, has the same shape as the bed but with much reduced relief. The damping of the relief is the same both along and across the flowline, suggesting that lateral velocity fluctuations are not important and that flow around and between obstacles is not well developed at the surface or at depth. At two sites, however, the internal layer does not match the bed and at one of these there must be important thirddimensional flow at depth.
\end{abstract}

\section{INT RODUCTION}

The flow of the ice sheet leading to the deepdrilling site at Dye 3 has been studied on both a large scale and a small, more detailed scale. The detailed study area, discussed here, is located within the eastern cluster of the large-scale network of

*Institute of Polar Studies Contribution No.449. Geophysical and Polar Research Center Contribution No.412. observation points and is situated immediately upglacier of the drill site (Fig.1). The special feature of the detailed network is the closely spaced series of observations of surface velocity, accumulation rate, ice thickness, and internal layer depth carried out along three parallel lines. Certain results from the large-scale study for ice movement (Drew and Whillans 1984), firn stratigraphy, temperature and snow accumulation (Bow in press), and radar sounding (Jezek and others in press, Overgaard and Gundestrup in press) are also used here.

The detailed program is designed to support the interpretation of the results from the deep drilling and to describe the manner by which the ice sheet negotiates hills and valleys in the bed. The latter is the subject of the present report. We find that, at the surface, the flow is much less complex than anticipated, and that lateral flow variations are much less important than longitudinal variations. At depth, however, the story is mixed: there are two sites where the flow is not simple, but for largescale features on most of the strain network the data are consistent with flow at depth being in the same direction as flow at the surface.

In this regard a distinction is made between planar and non-planar flow. In planar flow the velocity vectors along a vertical column through the ice sheet all lie in a single plane but simple thirddimensional convergence or divergence is allowed. Non-planar flow involves deep ice travelling in different directions than shallow ice.

THE DATA

A map view of the detailed strain network is shown in Figure 2(a). Data were collected along three rows, labelled $A, B$ and $C$, about $2 \mathrm{~km}$ (one ice thick- 


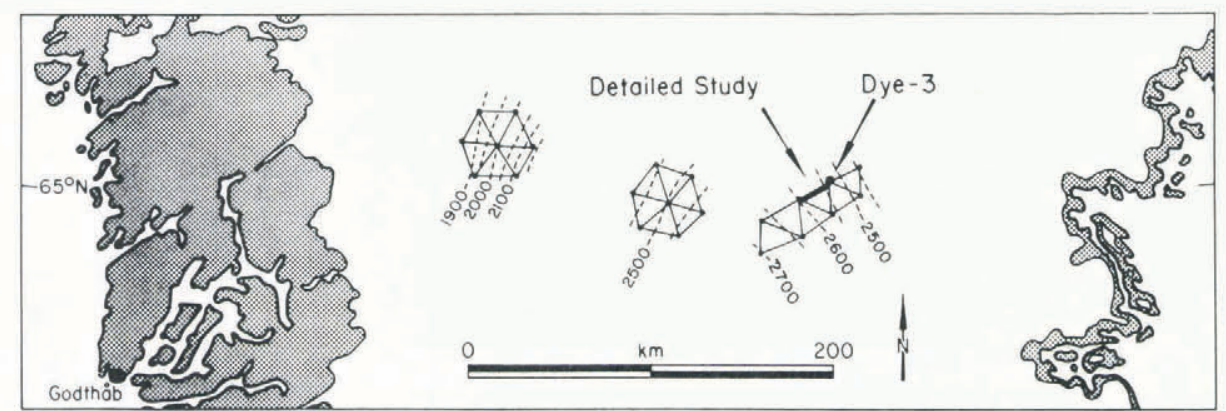

Fig.1. Southern Greenland. The detailed strain network is south-west and up-glacier from Dye 3.

ness) apart. Movement is left to right in the figure and each dot represents the site of a velocity determination; these are summarized in Table I. The Dye 3 bore hole is near station B1 (Table I). The network contains stations 3003 (at A1) and 3005 (between All and A12) of the large-scale study, and satellitedetermined movements of these stations provide absolute velocity and orientation reference. Relative movements with in the detailed network were obtained by repeated trilateration using Hewlett-Packard Model $3808 \mathrm{~A}$ electronic distance meters and a subsequent simultaneous least-squares solution for coordinates. Velocity gradients are plotted in Figure $2(\mathrm{e})$ to (h) and, based on manufacturer's specifications and field conditions, should be accurate to 1 or $2 \times 10^{-5} \mathrm{a}^{-1}$. As indicated in Drew and Whillans (1984) there is an unexplained discrepancy with the satellite-determined length of the strain network but the disagreement is, at most, equivalent to $3 \times 10^{-5} \mathrm{a}^{-1}$ if distributed over the entire network, and does not affect the interpretation here.

Radar depth sounding of bottom topography was carried out along the detailed strain network and continuous profiles were recorded using 35 and $60 \mathrm{MHz}$ radars operated on the surface (Jezek and others in press and Overgaard and Gundestrup in press). Data were also collected along a 1 ine used by investigators from the State University of New York at Buffalo: that line is shown by the dots running at an angle to the three 1 ines of the strain network. The bottom topography presented in Figure $2(d)$ is derived primarily from the $35 \mathrm{MHz}$ data with supplementary interpretation using gravity data and is broadly compatible with the results of the $60 \mathrm{MHz}$ radar survey. The precision of both radar surveys is about $\pm 15 \mathrm{~m}$, but at a few locations near the bore hole the relative difference between bed elevations from the two data sets is $100 \mathrm{~m}$.
The large difference is primarily due to a reduction in the strength of the radar signal in the region about $5 \mathrm{~km}$ up-glacier of Dye 3 , where much of the interpretation relies on a combination of radar and gravity data.

Radio-reflecting horizons internal to the ice sheet were also recorded on the continuous profiles and the elevation of one of these is shown in Figure $2(c)$. The precision of these measurements is also about $\pm 15 \mathrm{~m}$. There is no apparent difficulty in tracing the radar layer along the $A, B$, and $C$ lines or between $\mathrm{Al}$ and $\mathrm{C} 1$ or $\mathrm{A} 12$ and $\mathrm{C} 12$.

Surface elevations (Fig.2(b)) were measured by hand-held pressure altimeter referred to the satellite tracking stations. Station $A 1$ is also station 3003 in Drew and Whillans (1984) and its elevation is $2490 \mathrm{~m} \mathrm{a.s.1.} \mathrm{The} \mathrm{contours} \mathrm{are} \mathrm{least} \mathrm{accurate}$ farthest from Dye 3, where the error may be $\pm 2 \mathrm{~m}$.

Accumulation rates were determined from measurements of gross-beta activity associated with nuclear explosions (Bow in press) and from repeated measurements of heights of bamboo poles. The first technique provides long-term averages for a few sites and the second detects short-distance variations more satisfactorily. The accumulation rate at $\mathrm{A} 12$ is $0.444 \mathrm{Mg} \mathrm{m}^{-2} \mathrm{a}^{-1}$. No systematic short-distance variations were detected. The variations suggested by Reeh and others (in press) for this region are smaller than the variability of the data obtained with bamboo poles.

\section{FLOW PATTERN}

Surface velocity vectors (Fig.2(a)) are nearly parallel to one another and show a turning to the right. From one end of the network to the other, velocities increase about as expected for balance with the net surface snow accumulation, although

TABLE I. COORDINATES IN 1980 (m) AND HORIZONTAL-VELOCITY COMPONENTS $\left(\mathrm{m} \mathrm{a}^{-1}\right)$

\begin{tabular}{|c|c|c|c|c|c|c|c|c|c|c|c|c|c|c|c|c|c|c|}
\hline \multicolumn{2}{|c|}{ Station } & $x$ & \multicolumn{2}{|r|}{$y$} & $u_{x}$ & $u_{y}$ & \multicolumn{2}{|c|}{ Station } & $x$ & $y$ & $u_{x}$ & $u_{y}$ & \multicolumn{2}{|c|}{ Station } & $x$ & y & $u_{x}$ & $u_{y}$ \\
\hline Al & & -3 & 1 & 944 & 13.130 & -0.429 & B1 & & 0 & 181 & 13.392 & -0.190 & $\mathrm{Cl}$ & & -2 & -1753 & 13.924 & -0.141 \\
\hline$A 2$ & -1 & 924 & 1 & 940 & 11.863 & -0.118 & B2 & -1 & 924 & -1 & 12.236 & 0.190 & $\mathrm{C} 2$ & -1 & 924 & -1870 & 12.226 & 0.213 \\
\hline A3 & -3 & 327 & 1 & 941 & 11.091 & 0.088 & B3 & -3 & 189 & -2 & 11.374 & 0.213 & C3 & -3 & 215 & -1871 & 11.345 & 0.306 \\
\hline A4 & -5 & 069 & 1 & 944 & 10.757 & 0.089 & B4 & -5 & 028 & 11 & 10.903 & 0.293 & $c 4$ & -5 & 072 & -1869 & 11.237 & 0.372 \\
\hline A5 & -6 & 731 & 1 & 948 & 10.673 & 0.379 & B5 & -6 & 890 & 2 & 10.999 & 0.414 & $\mathrm{C} 5$ & -6 & 827 & $\begin{array}{ll}-1 & 871\end{array}$ & 11.160 & 0.321 \\
\hline A6 & -8 & 688 & 1 & 950 & 9.959 & 0.834 & B6 & -8 & 871 & 1 & 10.304 & 0.654 & C6 & -8 & 677 & -1872 & 10.757 & 0.483 \\
\hline A7 & -10 & 621 & 1 & 966 & 9.406 & 0.975 & B7 & -10 & 752 & 1 & 9.702 & 0.960 & C7 & -10 & 399 & -1871 & 10.400 & 0.685 \\
\hline$A 8$ & -12 & 582 & 1 & 986 & 9.368 & 0.883 & B8 & -12 & 646 & -1 & 9.494 & 1.069 & C8 & -12 & 441 & -1863 & 9.778 & 1.187 \\
\hline A9 & -14 & 440 & 2 & 003 & 9.276 & 0.938 & B9 & -14 & 574 & 0 & 9.514 & 1.158 & C9 & -14 & 428 & -1860 & 9.629 & 1.211 \\
\hline A10 & -16 & 340 & 2 & 023 & 8.623 & 1.149 & $\mathrm{~B} 10$ & -16 & 474 & 0 & 9.126 & 1.147 & $\mathrm{ClO}$ & -16 & 410 & -1846 & 9.268 & 1.253 \\
\hline A11 & -18 & 198 & 2 & 045 & 8.002 & 1.208 & B11 & -18 & 298 & 0 & 8.121 & 1.320 & C11 & -18 & 293 & -1877 & 8.693 & 1.383 \\
\hline A12 & -20 & 120 & 2 & 074 & 7.534 & 1.263 & 812 & -20 & 070 & -1 & 7.845 & 1.328 & C12 & -20 & 236 & -1937 & 8.332 & 1.605 \\
\hline Mock & & -269 & & 346 & 13.048 & -0.209 & & & & & & & & & & & & \\
\hline $3005 x$ & -19 & 147 & 2 & 059 & 7.771 & 1.246 & & & & & & & & & & & & \\
\hline
\end{tabular}




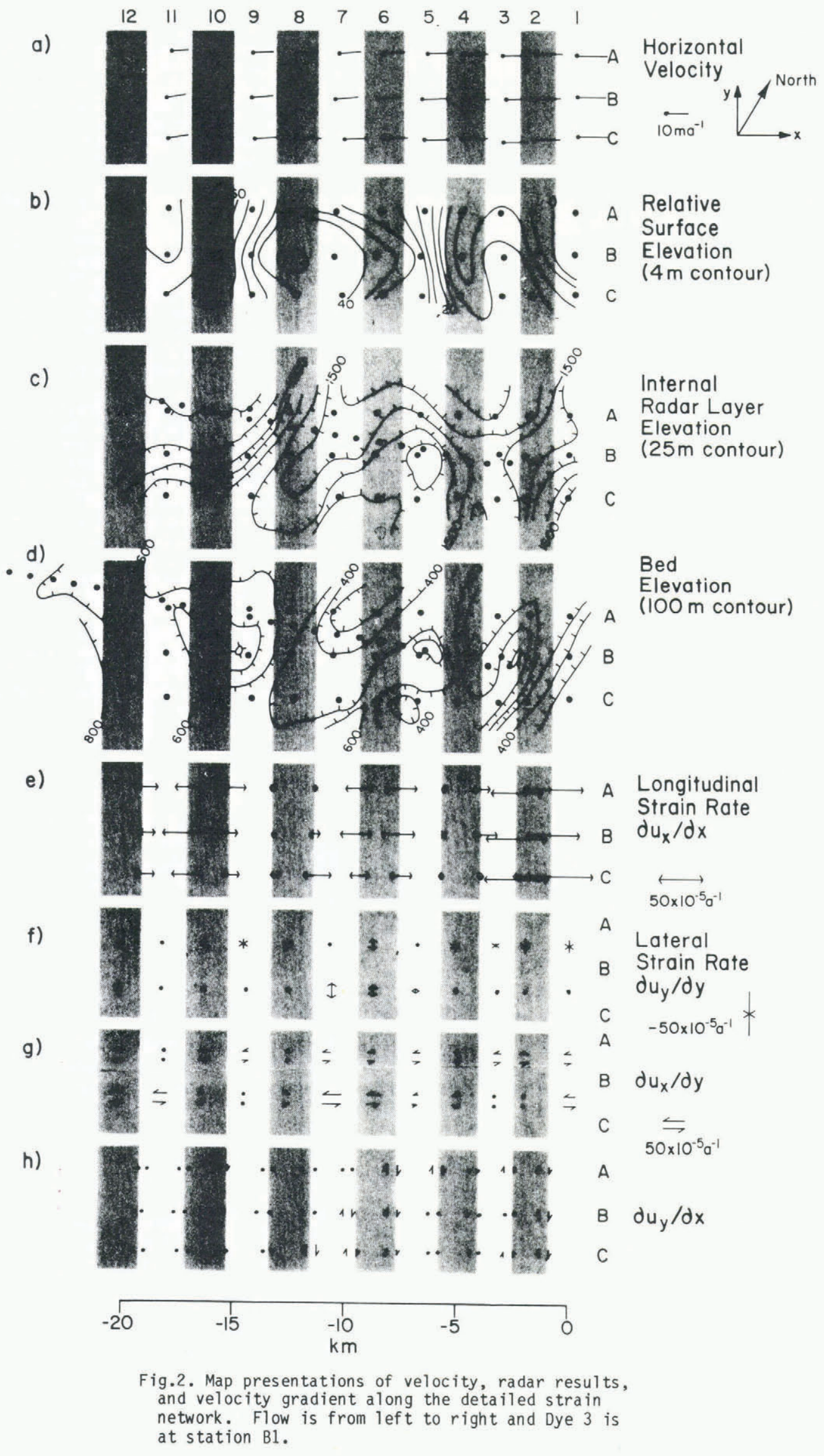


there are local exceptions as discussed below.

The bed (Fig.2(d)) is characterized by several irregularly-shaped knolls separated by deep valleys striking to the north and south. In general, the topography under the strain network is less rugged than the terrain farther up-glacier and nearer the ice divide (Jezek and others in press). Numerous diffraction hyperbolae observed on the flanks of the hill hill near B5 suggest that the bottom is rough on a scale of several tens of meters. The ice thickness varies by as much as $20 \%$ with in the strain network.

As has been generally found elsewhere, the surface elevation (Fig.2(b)) drops in steps over the basal highs (Fig.2(d)) with the steepest surface slopes where the ice is thinnest; good examples are found between $\mathrm{B} 10$ and $\mathrm{B} 9$ and between $\mathrm{B} 5$ and $\mathrm{B} 4$.

The flow along the strain network is generally longitudinally extensive (Fig.2(e)). This is in accordance with near-parallel flowlines and progressively faster flow needed to export the net snow accumulation. Locally the longitudinal strain-rate varies between near zero and twice the average. The ice stretches more on the approach to basal obstructions, and the variations in longitudinal velocity are roughly proportional to variations in ice thickness, but of opposite sign. Such a relationship is necessary between mean velocity and ice thickness to maintain continuity in ice flux. It is significant that the relationship also applies for surface velocity. This indicates that, at depth, divergence around or convergence between obstacles is not important to the overall ice flux. Also, because surface velocities vary as mean velocities, most of the shear must be in deep layers. Thus the flow appears to be planar and the main thickness moves almost as a block. This conforms to generally accepted theory and is as found near Byrd station, Antarctica (Whillans 1977).

At the surface, flow and flow variations in the lateral direction are much weaker than those in the longitudinal direction. The pattern of lateral strainrate (Fig.2(f)) nevertheless shows divergence on the approach to the ridge between $\mathrm{C} 6$ and $\mathrm{B} 5$ and lateral convergence into valleys located at $\mathrm{A} 1, \mathrm{~A} 3$, and $\mathrm{A} 7$. This is as normally expected for flow avoiding highs and favoring valleys, but the effect is weak. At the up-glacier end of the network, the lack of lateral divergence approaching the hill at Blo is unexplained. The convergence between $\mathrm{B} 12$ and $\mathrm{C} 12$ may be associated with flow in the lee of a basal high reported by Overgaard and Gundestrup just up-glacier (not shown on our map).

The velocity gradients $\partial u_{x} / \partial y$ contrast longitudinal variations of neighboring flowlines. There is an average shear such that flow along the $C-l$ ine is faster than along the A-line. Superimposed on this are local variations indicating that velocities are higher where the ice is thin than they are where the ice is thicker. This is in the expected sense to maintain volume flux. There is no tendency for "streaming", which would be the opposite effect, in which ice in valleys would travel faster and follow the axes of the valleys.

The final set of velocity gradients, $\partial u_{y} / \partial x$ $(F i g .2(h))$, shows deflection of the flowline by basal obstacles. The deflection is to the right and is also clear in the turning of the velocity vectors (Fig.2(a)). These gradients can be combined with $\partial u_{x} / \partial y$ to show east-west stretching: where $\left|\partial u_{y} / \partial x\right|$ is large, ice on the right-hand flowline is passing over a basal high first, accelerating, and pulling neighboring ice with it. The effect is small. (Similar gradients near $-20 \mathrm{~km}$ are calculated for a coordinate system aligned with the velocity vectors rather than the $x$-axis.)

Summarizing the velocity data, we find that most velocity variations are along the flowline. That is, gradients of $u_{y}$, in our coordinate system, are much less than those of $u_{x}$. Presumably variations in $u_{x}$
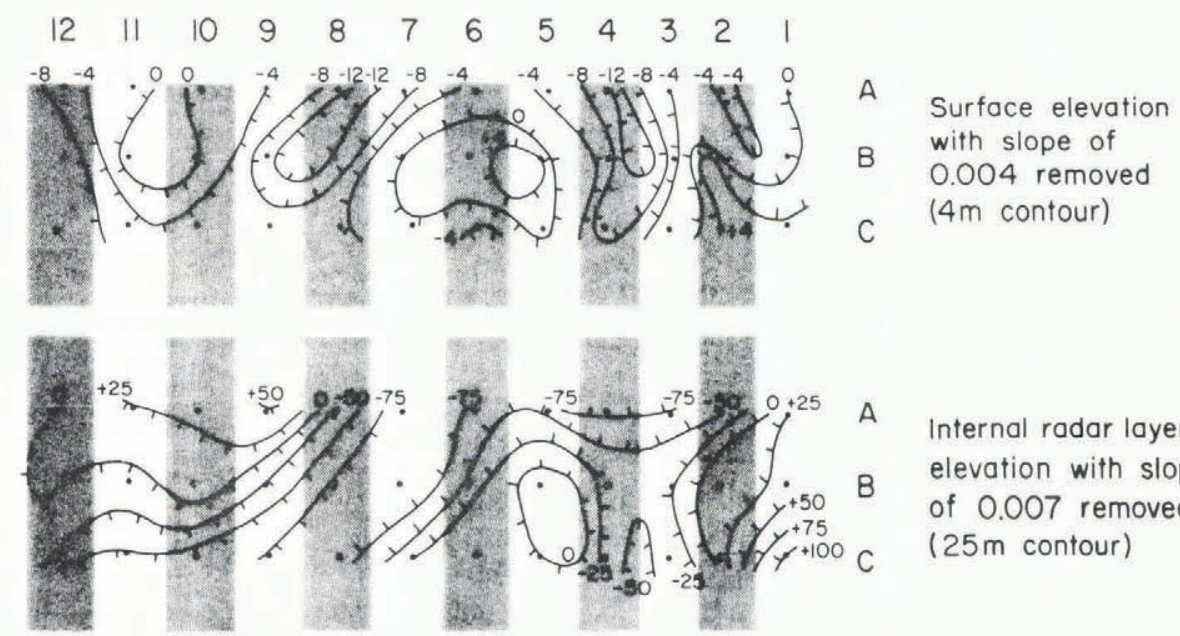

Internal radar layer elevation with slope of 0.007 removed ( $25 \mathrm{~m}$ contour)

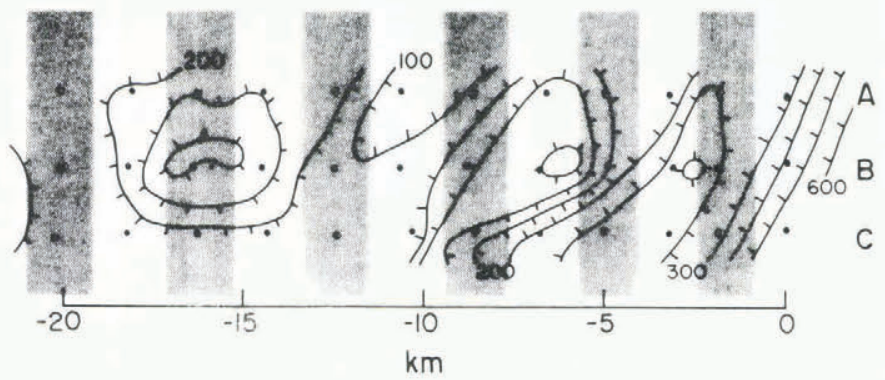

Bedrock elevation with slope of 0.025 removed ( $100 \mathrm{~m}$ contour)

Fig.3. Data for Figure 2(b), (c), and (d) with regional slopes removed (slopes of $0.004,0.007$ and 0.025 removed, respectively). 
dominate because it is this, the main component of flow, impinging on basal features that leads to all flow variations. Nonetheless it is surprising that lateral variations in bottom topography have so little influence on ice flow at the surface.

To examine whether this condition persists with depth we study an internal radio-reflecting layer buried to about $1000 \mathrm{~m}$ depth (Fig.2(c)). Internal layers are of ten taken to be isochrones. If so, the shape of the layer should be indicative of flow at depth. Els ewhere the layers have been found to mimic the bottom topography (Robin and others 1969, Whillans 1977, Whillans and Johnsen 1983), al though the shape of the layer is generally much smoother. In central East Antarctica, however, Robin and Millar (1982) found sites where the layering does not mimic the bottom but shows much more complex features, or is absent. They interpret this to indicate flow around obstacles in the bed.

Figure 3 shows the topographic maps of Figure 2(b), (c) and (d) with regional gradients removed in order to display better the relations between local variations. The data show the internal layer following the bed in most places. For example, there are hills at B5 and valleys at B7 in both bed and internal layer with the internal-layer relief being about $25 \%$ that of the bed. At this site the damping is isotropic: the ratio of internal layer to bed relief is about the same in both longitudinal and lateral directions. This is also true at the surface (Fig.2(b)) where there are important lateral slope variations. It is as if the bed relief were simply damped and, in the case of the surface, phase-shifted up-glacier. The damping is due to faster flow over obstacles and consequent longitudinal stretching and vertical thinning of the ice between the internal layer and the bed. If there were changes in flow direction at depth (non-planar flow) ice would be advected under or away from under the surface flowlines, and the internal layer would not correlate with the bed beneath it. Similarly, if ice in some of the valleys were nearly stagnant then these sites would be identified by an anomalously high internal layer. The correlation is, in many places, strong, albeit not perfect, and planar flow describes adequately the major part at these sites.

There are, however, two locations where the internal layer has a form very different from the bed. The basal hill at $B 10$ and $B 9$ has almost no corresponding expression in the internal layer. There the contours of internal-layer elevation are nearly perpendicular

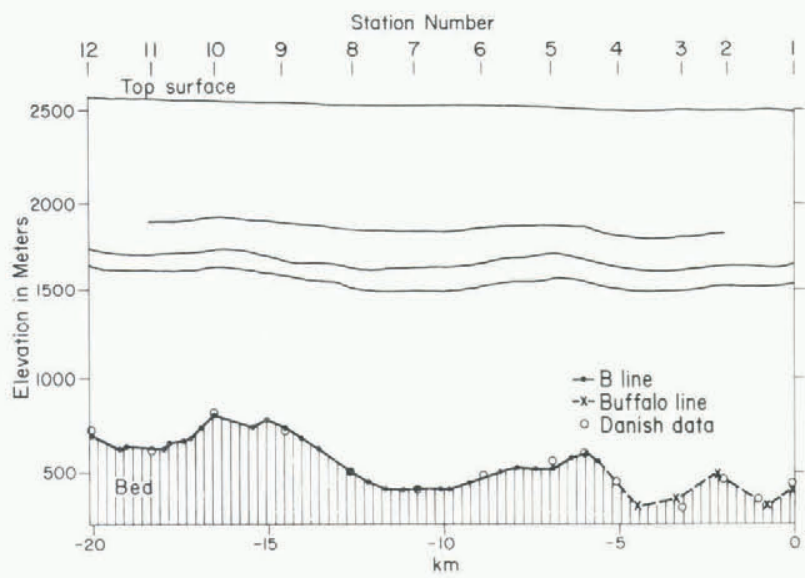

Fig.4. Profile along B-line. Solid and dashed lines are from $35 \mathrm{MHz}$ radar. Dashed bed represents bottom reflections obtained on a line $\approx 100 \mathrm{~m}$ to the southeast of B-line. The deepest internal layer is also shown in Figure 2(c). All layers show the same pattern of deformation. Open dots at bed are results from the $60 \mathrm{MHz}$ radar. to the contours of bottom topography. There is a weak influence of the bed in cross-section (Fig.4) but it is subdued compared to the rest of the survey. The narrow subglacial valley near the down-glacier end of the survey is the second example, but this is more easily understood because the valley is a much smaller feature than the hill near B9 and B10.

If the proposition that the internal layer follows an isochrone is maintained, then these data indicate that flow at depth is different from that at the surface. This could be because of stagnant ice near the bed (Colbeck and others 1978, Russell-Head and Budd 1979: 126) or because of changes in lateral convergence or divergence with depth at these sites.

According to the first suggestion of nearly stagnant ice, there would be an apparent ice bottom that is smoother than the bed. However, surface velocity variations (Fig.2) up-glacier from B10 seem to follow closely the changes in the bed and not a smoother effective bed. It seems that there the ice below the anomalous internal layer participates normally in ice flow and is not nearly stagnant. Relatively stagnant ice in the valley from C2 to Al remains a possibility, however.

Support for more stagnant ice near the bed near Dye 3 comes from the observation of silty ice in the lower $50 \mathrm{~m}$ of the Dye 3 core whose sedimentary stratigraphy is not well developed compared to the ice above (Dansgaard and others 1982). If that interpretation is correct then this ice is not part of the main flow of the glacier, and is much older than the ice above. The valley is narrow, and models of the influence of bed variations on ice flow (for example, Whillans and Johnsen 1983, Reeh and others in press) indicate that short wavelength features affect flow only near the bed.

For the anomalous site up-glacier from B10 we favor the suggestion that lateral convergence or divergence changes with depth (non-planar flow). Perhaps at depth near A10 there is more lateral convergence of flowlines than near the surface. Then, because ice is incompressible vertical thinning of deep ice would be anomalously small and a layer of given age would be anomalously high above the bed. Such behavior is more probable near the ice divide where the flow is less directed. Farther down-glacier, where the flow is more consistent, such anomalous ice from near the ice divide is drawn out and thinned, and so is not evident in our study.

\section{INTERPRET ATION}

This qualitative description of ice flow over a rugged terrain provides insight into the interaction of the ice sheet with its bed. The terrain is rough, showing changes of $400 \mathrm{~m}$ in distances of $2 \mathrm{~km}$, but the flow seems to be comparatively simple.

The flow variations are mainly in the longitudinal direction at the surface and apparently also at depth. Effects of important non-planar flow (in which velocity vectors change geographic direction with depth) are not evident for major features over most of the network.

Flow around obstructions (non-planar flow) must certainly be important very close to the bed, but it seems that the main body of the glacier reacts only to large-scale features in the direction of flow (the wavelength of variation at the surface is 5 to $8 \mathrm{~km}$, or 2.5 to 4 times the ice thickness). Neighboring flowlines vary according to their separate bed forms and are not greatly influenced by topography to the sides. This differs from flow in a floating ice shelf where drag at the walls or around islands dominates. Near Dye 3 the flow is affected mainly by obstructions directly beneath the flowline.

Overall, the glacier has adjusted to basal obstructions by building slightly in thickness behind them. This causes steeper slopes over obstructions. In a manner analogous to water flow over a weir, the 
glacier accelerates on the approach to the thinner region.

The mechanistic link between surface, bed topography and speed variation involves changes in shear stresses on horizontal planes. According to the standard formula, shear stresses are larger where slopes are steeper. These larger stresses lead to the faster flow needed to pass the ice flux through the reduced thickness.

An equivalent description of this process has been applied to related data near Byrd station, Antarctica (Whillans and Johnsen 1983). In that description the glacial surface is viewed as being higher than average behind an obstruction. The extra weight causes extra horizontal stretching of the glacier and faster velocities over the obstruction. Short wavelength basal features have little gross effect.

The forms of the internal layer over the narrow valley near the core hole and at the up-glacier end of the network do not correlate with the bed. The narrow valley is only weakly apparent in the internal layer or in surface topography or strain-rate: presumably ice in the valley does not fully participate in the main flow (as predicted by theory assuming planar flow). At the second special site, near B12, the anomalously $\mathrm{high}$ internal layer indicates extra relative thickening of the ice below it. There are no special features in the bed up-glacier of this site (Overgaard and Gundestrup in press) that can explain such behavior, but the site is only ten ice thicknesses from the ice divide, and flow near ice divides is less well-directed (less planar) than farther downglacier.

The different behavior near $\mathrm{B} 12$ is attributed to its proximity to the ice divide, but the most pronounced three-dimensional feature under the network is the hill, also situated there. The other hills are ridges aligned diagonally to the flow. Perhaps the flow is everywhere more complex than the data seem to suggest but the diagonal ridges and valleys cause flow that appears more simple than it is.

The data are too 1 imited in extent to determine whether planar or non-planar flow dominates in this part of Greenland. The planar-flow model works well near Byrd station (Whillans and Johnsen 1983) but not in certain places in East Antarctica (Robin and Millar 1982). Near Dye 3 it describes long wavelength features for the $15 \mathrm{~km}$ nearest to the core hole, but not features between 15 and $20 \mathrm{~km}$.

\section{ACKNOWLEDGEMENTS}

We thank Richard Alley for very valuable help and discussions. This work was supported by National Science Foundation grant nos. DPP-8008356 and 8306689 .

\section{REFERENCES}

Bow W A In press Isotopic diffusion in polar firn. ohio State University. Institute of Polar Studies. Report

Colbeck S C, St Lawrence W, Gow A J 1978 Creep rupture at depth in a cold ice sheet. Nature 275 (5682): 733

Dansgaard W and 6 others 1982 A new Greenland deep ice core. Science 218(4579): 1273-1277

Drew A R, Whillans I M 1984 Measurement of surface deformation of the Greenland ice sheet by satellite tracking. Annals of Glaciology 5: 51-55

Jezek K C, Roeloffs E A, Greischer L L In press A geophysical survey of subglacial geology around the deep-drilling site at Dye-3, Greenland. American Geophysical Union, GISP Monograph

overgaard S, Gundestrup N In press Bedrock topography of the Greenland ice sheet in the Dye-3 area. Amemican Geophysical Union, GISP Monograph

Reeh $\mathrm{N}$, Johnsen S J, Dahl-Jensen D In press Dating the Dye-3 ice core by flow-model calculations. Amemican Geophysical Union, GISP Monograph
Robin G de Q, Millar D H M 1982 Flow of ice sheets in the vicinity of subglacial peaks. Annals of Glaciology 3: 290-294

Robin G de Q, Evans S, Bailey J T 1969 Interpretation of radio echo sounding in polar ice sheets. Philosophical Transactions of the Royal Society of London Ser A 265(1166): 437-505

Russell-Head D S, Budd W F 1979 Ice-sheet flow properties derived from bore-hole shear measurements combined with ice-core studies. Joumal of Glaciology 24(90): 117-130

Whillans I M 1977 The equation of continuity and its application to the ice sheets near "Byrd" station, Antarctica. Joumal of Glaciology 18(80): 359-371

Whillans I M, Johnsen S J 1983 Longitudinal variations in glacial flow: theory and test using data from the Byrd station strain network, Antarctica. Journal of Glaciology 29(101): 78-97 